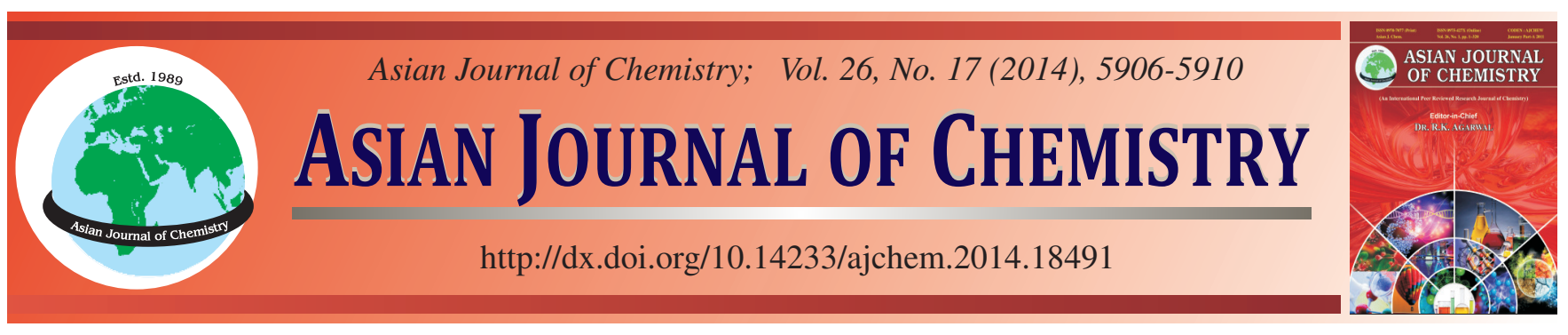

\title{
Optimized Extraction of Total Flavonoid Content of Pummelo Peel by Response Surface Methodology and Their Antioxidant Activity $\dagger$
}

\author{
Li-Qin JiAnG ${ }^{*}$, XIAO-FAng SHEN and DAO-ZhONG XIA
}

Department of Pharmacy, Zhejiang Chinese Medical University, Hangzhou 310053, P.R. China

*Corresponding author: E-mail: jiang@zcmu.edu.cn

The aim of this work was to optimize extraction total flavonoid from Guangxi Pummelo peels by response surface methodology and study the antioxidative activity of the extraction. The effects of ethanol concentration, ratio of solid to liquid, extraction time and temperature on the yield of total flavonoid were assessed. The yield of total flavonoid under analysis optimum condition was also fore casted by DesignExpert Software 7.0 software. Antioxidant activity of the extract was evaluated by study scavenging capacity of hydroxyl radical and superoxide anion radical, respectively. The optimized extraction conditions were as follows: extraction with a 38 fold volume of $80 \%$ aqueous ethanol solution for $1.75 \mathrm{~h}$ at $56^{\circ} \mathrm{C}$. Under these conditions, the theoretical yield of total flavonoid was $7.25 \%$ and the extract possessed high antioxidative activity. This method is scientific, reasonable and feasible. It also laid the foundation for research and application of total flavonoid in Pummelo peel.

Keywords: Pummelo peel, Total flavonoids, Ultrasonic-assisted extraction, Response analysis, Antioxidation activity.

\section{INTRODUCTION}

Citrus belongs to one of the most desirable fruits and is widely used in food industries for producing fresh juice, citrusbased drinks and cans. Guangxi Pummelo belongs to citrus, grow mainly in Guangdong, Guangxi, Fujian, Yunnan and Taiwan province of China. Pummelo peels, a by-product of Guangxi Pummelo, which may account for up to $50 \%$ of the total fruit weight, are rich in numerous biologically active compounds such as phenolic acids, flavonoids and essential oil $^{1-4}$. Flavonoids have been found to possess antiallergenic, antithrombotic, anti-inflammatory, antimicrobial, antioxidant, antithrombotic, cardioprotective and vasodilatory effects. These compounds have been associated with healthy properties ascribed to their antioxidant activity and free radical scavenging abilities ${ }^{5-9}$. The dried Pummelo peel is taken to cure cold as traditionally medicine in China.However, large amount of Pummelo peels were discarded, which cause the waste of resources and environmental pollution. Pummelo by-products, if utilized fully could be a source of flavonoid to utilize in food industry.

The biologically functional flavonoids from various plants were isolated by extraction method such as maceration and Soxhlet extraction method. However, these conventional extraction methods were generally time-consuming and had low efficiency ${ }^{10}$. Ultrasound-assisted extraction has been widely applied in extraction of flavonoids from different botanic materials ${ }^{11}$. Although ultrasonic extraction of bioactive compounds from botanic materials was greatly popular, the investigation of locally ultrasonic irradiation in extraction of flavonoids from Pummelo peel has little reported. Therefore, the objective of this work is to study the local effect of ultrasonic irradiation on total flavonoid. To evaluate contribution of each ultrasonic variable and obtain the optimal ultrasonic conditions, a response surface methodology (RSM) using Box-Behnken design was applied to optimize the procedure. Furthermore, the antioxidant activity of the extract was evaluated by study scavenging capacity of hydroxyl radical and superoxide anion radical, respectively. This study provides theoretical and technical support for the development and utilization of flavonoids in Pummelo peel.

\section{EXPERIMENTAL}

Rutin standard (AR, China Biological Products Offices), Ascorbic acid (AR, Guangdong Guanghua Chemical Company Ltd.), sodium nitrate, aluminum nitrate, sodium hydroxide, $30 \%$ hydrogen peroxide, ferrous sulfate, salicylic 
acid, pyrogallol, tris(hydroxymethyl aminomethanem), ethanol, hydrochloric acid, etc. All reagents were analytically pure. XMTD-204 digital water bath (Shanghai Meixiang Instrument co., Ltd.), FW135 herbal disintegrator (Tianjin Taisite Instrument Co., Ltd.), digitally controlled ultrasonic device(Kunshan Ultrasonic Instrument Co., Ltd.), BS 224S automatic analytical balance (Beijing Sartorius Instrument System co., LTD.), R201 rotary evaporation apparatus (Shanghai Shensheng Bio-tech co., LTD.).

Sample collection and pretreatment: Guanxi Pummelo was purchased in the market and peeled. The peel was washed thoroughly by potable water and then dried in hot air oven at $60{ }^{\circ} \mathrm{C}$. Dried peel were powdered using a herb disintegrator and subsequently sieved (60 mesh), then stored at $-20^{\circ} \mathrm{C}$ until analysis.

Preparation of sample solution: Ultrasonic-assisted extraction (UAE) were performed in a digitally controlled ultrasonic device. Working frequency was fixed at $40 \mathrm{kHz}$. The extraction variables were selected according to Thoo et al. ${ }^{10}$. Dried Pummelo peel samples ( $5 \mathrm{~g}$ ) were extracted twice with the required solvent, temperature and time. Extracts were then filtered and the filtrate was prepared with a constant volume (100 mL) using $60 \%$ ethanol for estimation of flavonoids and antioxidant measurements through various chemical assays. Each extraction was performed in duplicate and all analyses were performed in triplicate.

Total flavonoids content determination: Total flavonoid content (TFC) in extracts was determined according to the colorimetric method with little modification ${ }^{12}$, using the aluminum nitrate colorimetric method. The reaction mixture contained $2 \mathrm{~mL}$ of extract and $0.8 \mathrm{~mL}$ of $5 \%$ sodium nitrite. After $6 \mathrm{~min}, 0.8 \mathrm{~mL}$ of $10 \%$ aluminium nitrite was added. In the next $6 \mathrm{~min}, 10 \mathrm{~mL}$ of $1 \mathrm{M}$ sodium hydroxide solution was added and the volume was increased to $25 \mathrm{~mL}$ (q.s. $30 \%$ ethanol). Immediately, the reaction mixture absorbance was measured by a spectrophotometer at $510 \mathrm{~nm}$ against a blank (control) and used to calculate total flavonoids content using rutin as a standard. TFC was expressed as rutin equivalents (RE), in mg RE per g DW.

Determination scavenging hydroxyl radicals ( $\left.{ }^{\circ} \mathrm{OH}\right)$ : The scavenging activity of the extract against the hydroxyl radicals was measured by an improved Fenton-type reaction ${ }^{13}$. In brief, $2 \mathrm{~mL}$ of $6 \mathrm{mM} \mathrm{FeSO}_{4}$ and $2 \mathrm{~mL}$ of sample solution at different concentrations or $\mathrm{VC}$ in ethanol were mixed and the reaction was started by addition of $2.0 \mathrm{~mL}$ of $6 \mathrm{mM} \mathrm{H}_{2} \mathrm{O}_{2}$. After this mixture was reacted for $10 \mathrm{~min}, 2.0 \mathrm{~mL}$ of $6 \mathrm{mM}$ salicylic acid was added and further reacted for $0.5 \mathrm{~h}$. Finally, the absorbance was recorded at $510 \mathrm{~nm}$ and the scavenging activity of the extract was calculated according to the equation:

$$
\text { Scavenging activity on } \mathrm{E}(\mathrm{HO})(\%)=\left[1-\frac{\left(\mathrm{A}_{\mathrm{s}}-\mathrm{A}_{\mathrm{i}}\right)}{\mathrm{A}_{0}}\right] \times 100
$$

$\mathrm{A}_{\mathrm{s}}$ : Absorbance of the sample; $\mathrm{A}_{\mathrm{i}}$ : Absorbance of blank, while double distilled water was used instead of salicylic acid; $\mathrm{A}_{0}$ : Absorbance of control when double distilled water was used as a blank.

Determination of reduction superoxide anion radical $\left(\mathbf{O}^{2-}\right)$ rate: A method as described by Chen et al. ${ }^{14}$ was used to measure superoxide anion reduction ability with a minor modification. The reaction mixture contained $1 \mathrm{~mL}$ of sample solution prepared in distilled water, $5 \mathrm{~mL}$ of Tris- $\mathrm{HCl}$ buffer $(\mathrm{pH} 8.2)$ and $50 \mu \mathrm{L}$ of $50 \mathrm{mmol} / \mathrm{L}$ pyrogallol solution. After the mixture was vigorously blended and incubated at $25^{\circ} \mathrm{C}$ for $10 \mathrm{~min}$, the absorbance of the mixture was measured at $325 \mathrm{~nm}$ using a spectrophotometer. Ascorbic acid was used as a positive control. The reduction rate of superoxide radicals (\%) was calculated according to the following equation:

$$
\text { Reduction rate } \operatorname{RE}\left(\mathrm{O}_{2}{ }^{--} \%\right)=\left[\mathrm{A}_{0}-\frac{\left(\mathrm{A}_{\mathrm{s}}-\mathrm{A}_{\mathrm{i}}\right)}{\mathrm{A}_{0}}\right] \times 100
$$

where $A_{0}$ was the absorbance of the control (distilled water instead of sample); $A_{s}$ was the absorbance of the test sample mixed with the reaction solution; $\mathrm{A}_{\mathrm{i}}$ was the absorbance of the test sample mixed with reaction solution in which $\mathrm{HCl}(1.0$ $\mathrm{mM}$ ) instead of pyrogallol.

Response surface experiment design: Researches indicated that main factors affecting total flavonoid content extraction ratio were: ethanol concentration, reflux time and solid-liquid ratio. Response surface methodology was used to find out the optimal ultrasonic extraction conditions for total flavonoid. The extraction experiments were carried out according to a central composite design with five factors and three levels. The five independent variables selected for this paper were ethanol concentration $\left(\mathrm{X}_{1}\right)$, ultraction time $\left(\mathrm{X}_{2}\right)$, solid to liquid ratio $\left(\mathrm{X}_{3}\right)$, ultrasonic frequency $\left(\mathrm{X}_{4}\right)$ and extraction temperature $\left(\mathrm{X}_{5}\right)$ on the yield of flavonoids $(\mathrm{Y})$. For each factor, an experimental range was based on the results of preliminary single-factor experiments. Yield of the extracted total flavonoids was the dependent variable. The total design consisted of 30 experimental points and the experiments were carried out in a random order.

Data from the central composite design were analyzed by multiple regression to fit the following quadratic polynomial model:

$$
\mathrm{Y}=\mathrm{b}_{\mathrm{k} 0}+\sum_{\mathrm{i}=1}^{5} \mathrm{~b}_{\mathrm{ki}} \mathrm{x}_{\mathrm{i}}+\sum_{\mathrm{i}=1}^{5} \mathrm{~b}_{\mathrm{kii}} \mathrm{x}_{\mathrm{i}}^{2}+\sum_{\mathrm{i}=1}^{5} \mathrm{~b}_{\mathrm{kij}} \mathrm{x}_{\mathrm{i}} \mathrm{x}_{\mathrm{j}}
$$

where $\mathrm{Y}$ is the dependent variable, $\mathrm{b}_{\mathrm{k} 0}, \mathrm{~b}_{\mathrm{ki}}, \mathrm{b}_{\mathrm{kii}}$ and $\mathrm{b}_{\mathrm{kij}}$, are constant regression coefficients of the model, while $\mathrm{x}_{\mathrm{i}}, \mathrm{x}_{\mathrm{j}}$ are the independent variables.

According to the principle of central composite design, five levels in each factor with the code value $(-\alpha,-1,0,1, \alpha$ (three factors central composite design $\alpha=1.732$ ) were set and the total design consisted of 32 experimental points including six replications of the center points (all variables

\begin{tabular}{|c|c|c|c|c|c|}
\hline \multicolumn{6}{|c|}{$\begin{array}{l}\text { TABLE-1 } \\
\text { THREE FACTORS FIVE LEVELS } \\
\text { CENTRAL COMPOSITE DESIGN }\end{array}$} \\
\hline \multirow{2}{*}{ Factor } & \multicolumn{5}{|c|}{$\begin{array}{ll}\text { Level } \\
\end{array}$} \\
\hline & $-\alpha$ & -1 & 0 & 1 & $\alpha$ \\
\hline A: Ethanol conc. (mg/g) & 42.7 & 50 & 60 & 70 & 77.3 \\
\hline B: Reflux time (h) & 0.63 & 1 & 1.5 & 2 & 2.36 \\
\hline C: Solid- liquid ratio (g/g) & 1:9.07 & $1-12$ & $1: 16$ & $1: 20$ & $1: 22.9$ \\
\hline D: Extraction temp. $\left({ }^{\circ} \mathrm{C}\right)$ & 42.7 & 50 & 60 & 70 & 77.3 \\
\hline
\end{tabular}
were coded as zero) (Table-1). The 32 sets of experiments were performed in a random order. 
Data analysis: Data are expressed in the style of mean \pm standard deviation $(x \pm S D)$, using the statistical software SPSS 11.5 for Windows for analysis of variance. Significant levels were defined using the value $p<0.05$.

\section{RESULTS AND DISCUSSION}

Standard curve: The standard working curve of total flavonoid content is $\mathrm{Y}=1.389 \mathrm{X}+0.005\left(\mathrm{R}^{2}=0.9994\right)$.

Single factor experiments: Single factor experiments were applied to investigate whether ethanol concentration, solid to liquid ratio, extraction time and extraction temperature to determine appropriate experimental range for subsequent analyses.

Ethanol concentration on the effect of total flavonoid yield: Effect of ethanol concentration on total flavonoid yield is shown in Fig. 1, and shows it greatly influenced by ethanol concentration. Total flavonoid yield was parabolic with a maximum value at $80-90 \%$ ethanol and followed by a considerable decline with higher concentration of ethanol.

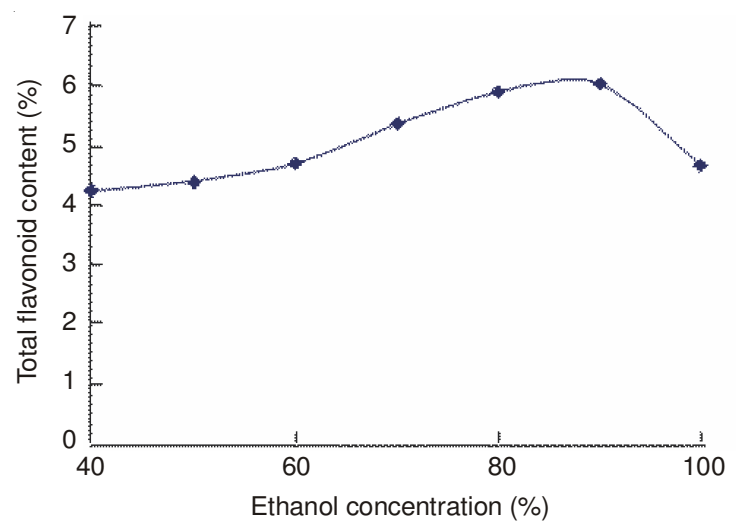

Fig. 1. Ethanol concentration on the effect of total flavonoid yield

Solid-liquid ratio on the effect of total flavonoid yield: The ratio of solid-liquid can affect the dissolution of flavonoid to aqueous ethanol. A suitable volume of ethanol solution facilitates the total dissolution of flavonoid from plant. As shown in Fig. 2, the higher the amount of solvent, the greater the contact area, the more fully immersed, the higher the yield of total flavonoid. The maximum yield of total flavonoid was achieved when solid-liquid ratio was 1:35. As the solid-liquid ratio continued to increase, more impurities such as polysaccharide and protein were dissolved, hindering the dissolution of flavonoid.

Ultrasonic extraction time on the effect of total flavonoid yield: Extraction time is one of the most important factors affecting extraction yield of flavonoid. Different extraction times would influence the solvent and solid matters contact. In this experiment, different times $(0.5 \mathrm{~h}, 1 \mathrm{~h}, 1.5 \mathrm{~h}, 2 \mathrm{~h}, 2.5 \mathrm{~h})$ were chosen to study the effect on extraction yield of flavonoid. As shown in Fig. 3, the longer the extraction time, the higher of total flavonoid. The maximum yield of total flavonoid was attained at the extraction time of $1.5 \mathrm{~h}$. As the extraction time increased above $1.5 \mathrm{~h}$, the yield of total flavonoid reduced. It could be implied that extraction time was too short to completely dissolve total flavonoid, but if the time is extra long, the concentration of active ingredients of extracts has reached equilibrium with little change of dissolution and there

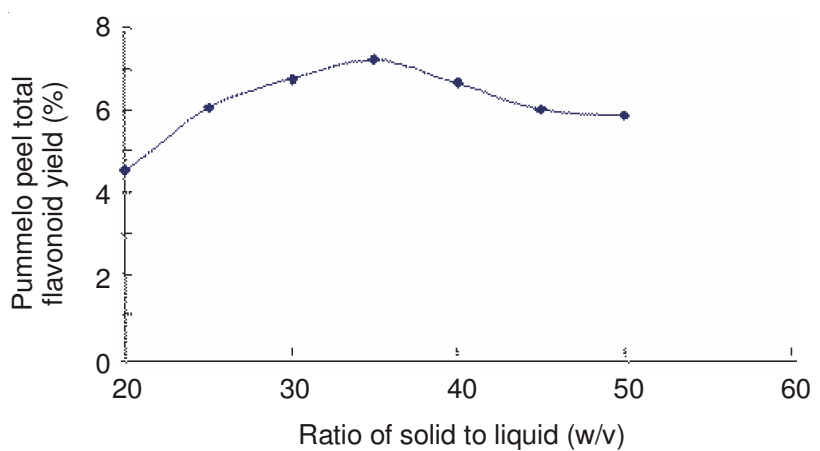

Fig. 2. Solid-liquid ratio on the effect of total flavonoid yield

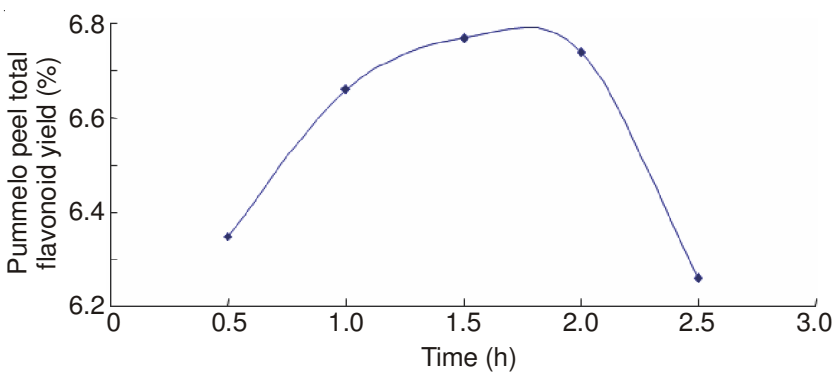

Fig. 3. Ultrasonic extraction time on the effect of total flavonoid yield

also may be adverse reactions causing the yield decline. In addition, in order to save energy and improve efficiency, the extraction time being set at $1.5 \mathrm{~h}$ was appropriate.

Extraction temperature on the effect of total flavonoid yield: High temperature solution will be conductive to dissolve flavonoid from plant, because high temperature can increase molecular movement. As shown in Fig. 4, when the extraction temperature increased from 40 to $80^{\circ} \mathrm{C}$, the extraction yield increased steadily. The maximum yield was obtained at $60^{\circ} \mathrm{C}$. This could be interpreted that, with an increase in temperature, molecular movement accelerated, increasing the solubility and leading to an increasing in yield. However, high temperature promoted negative reaction such as the oxidation, resulting in decreased yield of flavonoid.

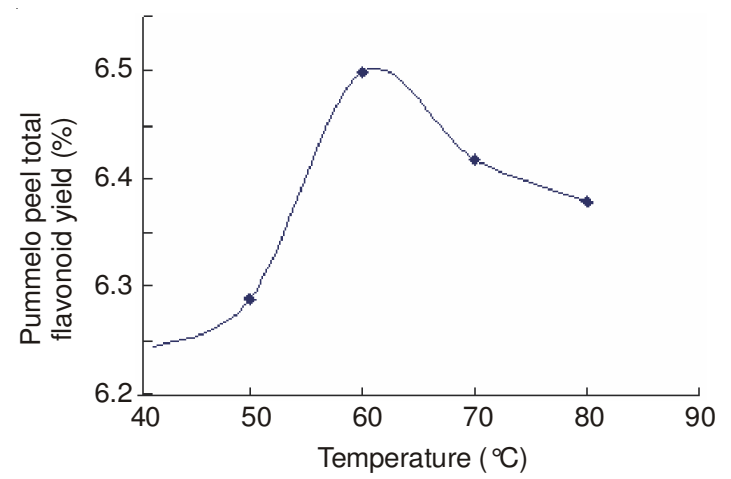

Fig. 4. Extraction temperature on the effect of total flavonoid yield

\section{Optimization of extraction parameters of total flavonoid yield}

Establishment of mathematical model: Response variable experimental data for optimization of total flavonoid is shown in Table-2. The statistical combination of the independent variables in code and natural values along with the predicted and experimental response is presented in Table-3. According to the sequential model, the sum of squares can be 


\section{EXPERIMENTAL DESIGN AND OBSERVED RESPONSE}

\begin{tabular}{|c|c|c|c|c|c|}
\hline No. & A & B & C & D & $\mathrm{TF}(\%)$ \\
\hline 1 & 0 & 0 & 0 & 0 & 6.62 \\
\hline 2 & 1 & -1 & 1 & -1 & 6.5 \\
\hline 3 & 0 & 0 & -1 & 0 & 6.65 \\
\hline 4 & -1 & -1 & -1 & -1 & 6.51 \\
\hline 5 & -1 & -1 & -1 & 1 & 6.18 \\
\hline 6 & 0 & 0 & 0 & -1 & 5.84 \\
\hline 7 & 0 & 0 & 1 & 0 & 7.11 \\
\hline 8 & 1 & 1 & 1 & 1 & 5.63 \\
\hline 9 & -1 & 1 & -1 & -1 & 6.78 \\
\hline 10 & 1 & 1 & -1 & 1 & 6.43 \\
\hline 11 & 1 & 0 & 0 & 0 & 5.25 \\
\hline 12 & -1 & -1 & 1 & -1 & 6.84 \\
\hline 13 & 0 & 0 & 0 & 0 & 6.86 \\
\hline 14 & -1 & 1 & -1 & 1 & 6.09 \\
\hline 15 & -1 & 0 & 0 & 0 & 6.61 \\
\hline 16 & 1 & -1 & -1 & -1 & 6.68 \\
\hline 17 & 0 & 0 & 0 & 0 & 6.72 \\
\hline 18 & -1 & 1 & 1 & 1 & 6.41 \\
\hline 19 & -1 & -1 & 1 & 1 & 6.76 \\
\hline 20 & -1 & 1 & 1 & -1 & 6.7 \\
\hline 21 & 0 & 0 & 0 & 0 & 6.72 \\
\hline 22 & 1 & 1 & -1 & -1 & 6.84 \\
\hline 23 & 0 & 1 & 0 & 0 & 6.56 \\
\hline 24 & 0 & 0 & 0 & 0 & 6.9 \\
\hline 25 & 0 & 0 & 0 & 1 & 6.81 \\
\hline 26 & 0 & -1 & 0 & 0 & 7.1 \\
\hline 27 & 0 & 0 & 0 & 0 & 6.72 \\
\hline 28 & 1 & -1 & -1 & 1 & 5.49 \\
\hline 29 & 1 & -1 & 1 & 1 & 5.4 \\
\hline 30 & -1 & 1 & 1 & 1 & 6.44 \\
\hline
\end{tabular}

A: Ethanol concentraction (\%), B: solid-liquid ratio, C: extraction time (h), D: extraction temperature $\left({ }^{\circ} \mathrm{C}\right)$.

\begin{tabular}{cccccc}
\multicolumn{7}{c}{ TABLE-3 } \\
\hline ANOurce & $\begin{array}{c}\text { Degree of } \\
\text { freedom }\end{array}$ & $\begin{array}{c}\text { Sum of } \\
\text { suqares }\end{array}$ & $\begin{array}{c}\text { Mean } \\
\text { square }\end{array}$ & F-Value & $p$-Value \\
\hline Model & 14 & 3.36 & 0.24 & 0.98 & 0.5103 \\
A-A & 1 & $1.67 \mathrm{E}-03$ & $1.67 \mathrm{E}-03$ & $6.84 \mathrm{E}-03$ & 0.0435 \\
B-B & 1 & 0.17 & 0.17 & 0.71 & 0.0412 \\
C-C & 1 & 0.015 & 0.015 & 0.062 & 0.8075 \\
D-D & 1 & 0.33 & 0.33 & 1.34 & 0.0265 \\
AB & 1 & 0.14 & 0.14 & 0.59 & 0.4535 \\
AC & 1 & 0.45 & 0.45 & 1.84 & 0.1949 \\
AD & 1 & 0.28 & 0.28 & 1.15 & 0.0481 \\
BC & 1 & 0.16 & 0.16 & 0.66 & 0.4306 \\
BD & 1 & 0.02 & 0.02 & 0.08 & 0.0387 \\
CD & 1 & $1.00 \mathrm{E}-02$ & $1.00 \mathrm{E}-02$ & 0.041 & 0.8422 \\
A2 & 1 & 1.43 & 1.43 & 5.86 & 0.0286 \\
B2 & 1 & $3.05 \mathrm{E}-04$ & $3.05 \mathrm{E}-04$ & $1.25 \mathrm{E}-03$ & 0.9723 \\
C2 & 1 & $2.31 \mathrm{E}-03$ & $2.31 \mathrm{E}-03$ & $9.45 \mathrm{E}-03$ & 0.9238 \\
D2 & 1 & 0.42 & 0.42 & 1.71 & 0.2105 \\
Residual & 15 & 3.66 & 0.24 & - & - \\
Lack of fit & 10 & 3.61 & 0.36 & 3.953 & 0.064 \\
Pure error & 5 & 0.046 & $9.14 \mathrm{E}-03$ & - & - \\
Cor total & 29 & 7.01 & - & - & - \\
\hline *Significant $(p<0.05)$. & & & &
\end{tabular}

obtained. The model, the sum of squares can be obtained. The models were selected based on the highest order polynomials where the additional terms are significant and the model is not aliased. The quadratic model was selected for the extraction yield determination (Figs. 5 and 6).
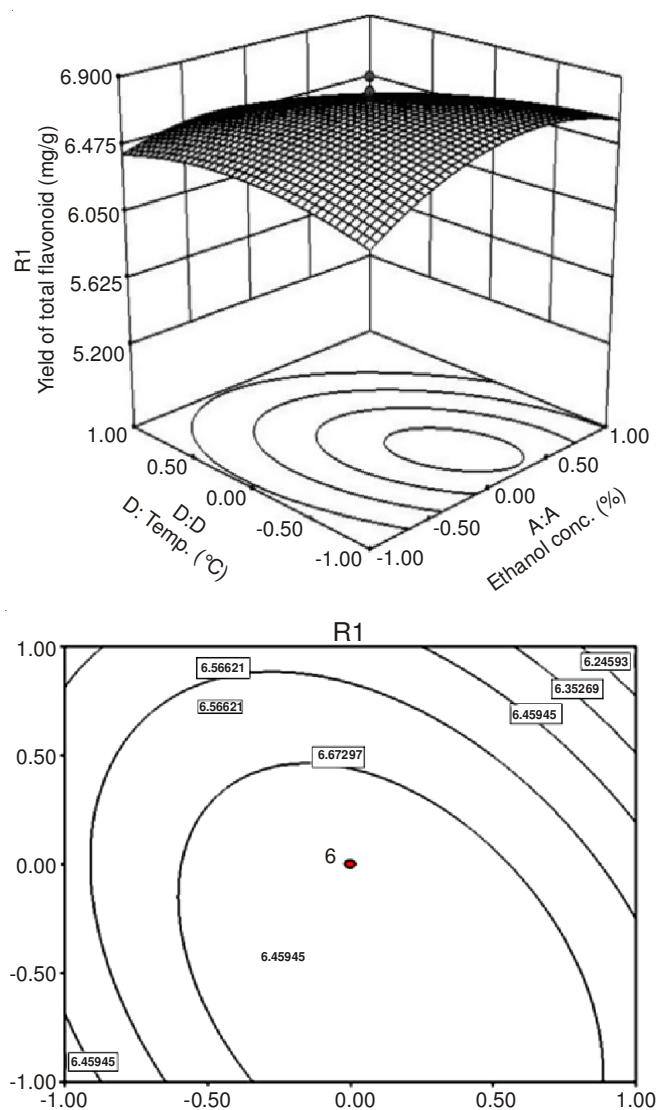

Fig. 5. Interaction between ethanol concentration and solid-liquid ratio
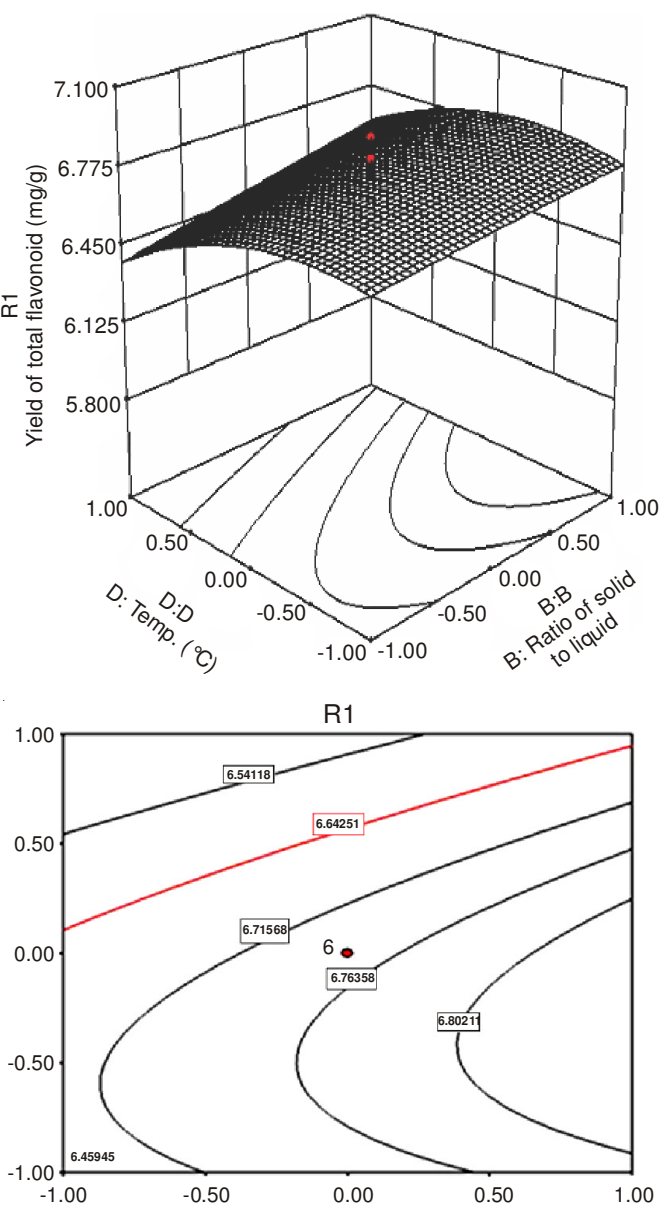

Fig. 6. Interaction between ethanol concentration and extraction temperature 
Using the designed experimental data (Table-2), the final empirical model in term of the coded factors after including the insignificant terms is shown as below:

$\mathrm{Y}=6.75-8.333 \mathrm{E}-003 \times \mathrm{A}+0.085 \times \mathrm{B}+0.025 \times \mathrm{C}-0.12 \times \mathrm{D}+$ $0.095 \times \mathrm{A} \times \mathrm{B}-0.17 \times \mathrm{AC}-0.13 \times \mathrm{AD}-0.100 \times \mathrm{BC}+0.035 \times$ $\mathrm{BD}+0.025 \times \mathrm{CD}-0.23 \times \mathrm{A} 2-3.333 \mathrm{E}-003 \times \mathrm{B} 2+9.167 \mathrm{E}-003$ $\times \mathrm{C} 2$

A: Ethanol concentraction \%, B: solid-liquid ratio, C: extraction time (h), D: extraction temperature $\left({ }^{\circ} \mathrm{C}\right)$.

Table-3 shows regional scale setting in this experiment. Interaction between ethanol concentration and the solid-liquid ratio, as well as the interaction between the ethanol concentration and extraction temperature, have a high effect on extraction yield of Pummelo peel total flavonoid.

Validation of the model: The optimal conditions (ethanol concentration $80.308 \%$, solid-liquid ratio 1:38.151, ul-trasonic extraction time $1.7506 \mathrm{~h}$, extraction temperature $56.535^{\circ} \mathrm{C}$ ) were obtained from the regression equation. Under the optimal condition, the maximum response value of yield ( $7.27 \%$ ) was predicted by the model. In order to validate the adequacy of the model, verification experiments were carried out under adjusted condition (ethanol concentration $80.3 \%$, solid-liquid ratio $1: 38$, ultrasonic extraction time $1.75 \mathrm{~h}$, extraction temperature $56^{\circ} \mathrm{C}$ ). Total flavonoid yield of $7.26 \%$ was obtained and the result was in good agreement with the predicted one. The result is accordant with previous study ${ }^{11}$.

Antioxidant activity of Pummelo peel flavonoids: Determination scavenging hydroxyl radicals $\left({ }^{\circ} \mathrm{OH}\right)$ of Pummelo flavonoid.

Determination of reduction superoxide anion radical $\left(\mathbf{O}^{2-}\right)$ rate of Pummelo flavonoid: Figs. 7 and 8 showed that with the increase of Pummelo peel flavonoids concentration, the ability of antioxidant was strengthened. According to the

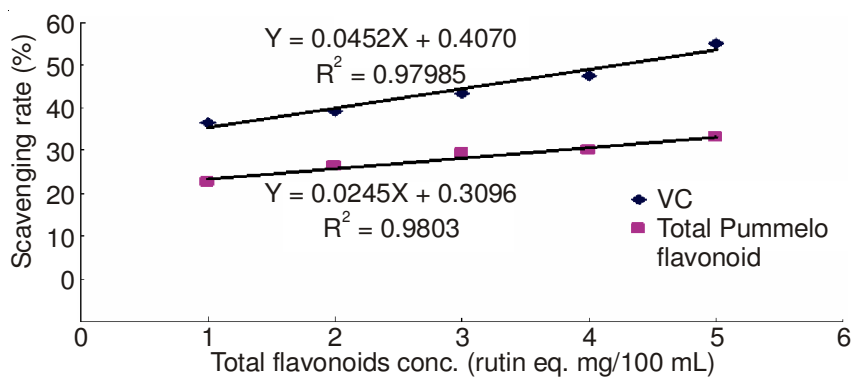

Fig. 7. Scavenging hydroxyl radicals $\left({ }^{\circ} \mathrm{OH}\right)$ activity of Pummelo peel flavonoid

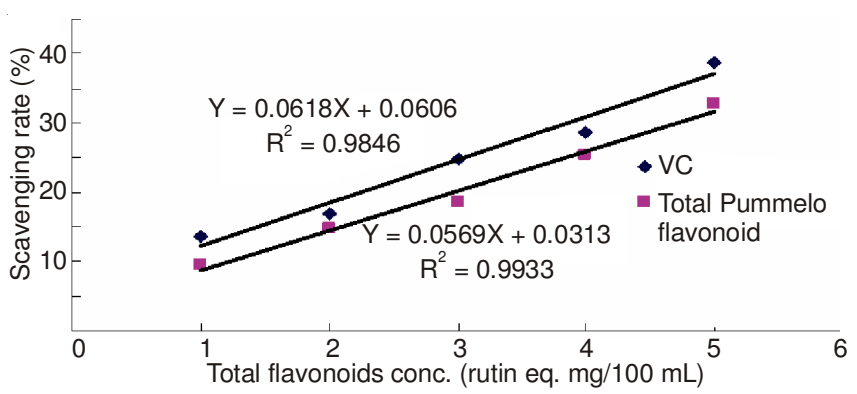

Fig. 8. Reduction superoxide anion radical $\left(\mathrm{O}^{2-}\right)$ rate of Pummelo peel flavonoid linear regression equation, $\mathrm{EC}_{50}\left({ }^{\circ} \mathrm{OH}\right)$ of Pummelo peel flavonoids was $7.78 \mathrm{mg} / 100 \mathrm{~mL}$, while $\mathrm{VC}$ was $2.04 \mathrm{mg} / 100 \mathrm{~mL}$. For $\left(\mathrm{O}^{2-}\right)$ reduction superoxide anion radical $\left(\mathrm{O}^{2-}\right)$ rate, $\mathrm{EC}_{50}$ of Pummelo peel flavonoids was $8.23 \mathrm{mg} / 100 \mathrm{~mL}$, while VC was $7.11 \mathrm{mg} / 100 \mathrm{~mL}$. Both indicated strong antioxidant activity in Pummelo peel flavonoid.

\section{Conclusion}

Ultrasound technique for the extraction of total flavonoid from Guangxi Pummelo peel was investigated. Ultrasound extraction has been shown to be an efficient method for extraction of flavonoid compounds extracted from Pummelo peel compared to methanol extraction. Ultrasound assist extraction resulted in an increase in maximum yield of flavonoid, reduction in extraction time, which is particularly favorable for extraction unstable components from vegetable materials. From single-factor experiments with total flavonoid extraction from Pummelo peel, response surface methodology could optimize the extraction process. Flavonoid contents was significantly correlated with antioxidative activity. Therefore, this work provides a high-yield technique for antioxidant extraction from Pummelo peel for food and functional food industry. Future studies to identify the predominant antioxidant compounds present in Pummelo peel and mechanisms of antioxidant activity are warranted.

\section{ACKNOWLEDGEMENTS}

The work was financial supported by Public Welfare Technology Application Research in Zhejiang province (2014C32115).

\section{REFERENCES}

1. M.Y. Kim, I.-J. Kim, S.J. Im, J.H. Kim, J.-M. Heo, S.-Y. Song, J.H. Kim, S.H. Moon and S. Cho, Nat. Prod. Res., (2014); doi:10.1080/ 14786419.2014.918123.

2. P.A. Dele, A.O. Jolaosho, O.M. Arigbede, V.O.A. Ojo, T.A. Amole, O.A. Okukenu and B.T. Akinyemi, Pak. J. Biol. Sci., 16, 1801 (2013).

3. J. Rao and D.J. McClements, Food Chem., 134, 749 (2012).

4. C.A. Manassero, J.R. Girotti, S. Mijailovsky, M. García de Bravo and M. Polo, Nat. Prod. Res., 27, 1475 (2013).

5. T. Yamada, S. Hayasaka, Y. Shibata, T. Ojima, T. Saegusa, T. Gotoh, S. Ishikawa, Y. Nakamura and K. Kayaba, J. Epidemiol., 21, 169 (2011).

6. J.A.S. Suryawanshi, Afr. J. Plants Sci., 5, 390 (2011).

7. S.I. Kang, H.S. Shin, H.M. Kim, Y.-S. Hong, S.-A. Yoon, S.-W. Kang, J.-H. Kim, M.-H. Kim, H.-C. Ko and S.-J. Kim, Biol. Pharm. Bull., 35, 223 (2012)

8. J.A. Nettleton, L.J. Harnack, C.G. Scrafford, P.J. Mink, L.M. Barraj and D.R. Jacobs Jr., J. Nutr., 136, 3039 (2006).

9. S.H. Moon, J.H. Lee, K.T. Kim, Y.-S. Park, S.-Y. Nah, D. Ahn and H.D. Paik, Int. J. Environ. Res. Public Health, 10, 5459 (2013).

10. Y.Y. Thoo, S.K. Ho, J.Y. Liang, C.W. Ho and C.P. Tan, Food Chem., 120, 290 (2010).

11. Y. Ma, X. Ye, Z. Fang, J.-C. Chen, G.-H. Xu and D.-H. Liu, Agric. Food Chem., 56, 5682 (2008).

12. S. Piccolella, A. Fiorentino, S. Pacifico, B. D' Abrosca, P. Uzzo and P. Monaco, J. Agric. Food Chem., 56, 1928 (2008).

13. N. Smirnoff and Q.J. Cumbes, Phytochemistry, 28, 1057 (1989).

14. X.D. Chen, X.Y. Yu, X.M. Hao, X. Lu and W. Wang, Food Res. Dev., 128, 20 (2007). 